\title{
The single mitochondrial chromosome typical of animals has evolved into 18 minichromosomes in the human body louse, Pediculus humanus
}

\author{
Renfu Shao, ${ }^{1,4}$ Ewen F. Kirkness, ${ }^{2,3}$ and Stephen C. Barker ${ }^{1,3}$ \\ ${ }^{1}$ The University of Queensland, Parasitology Section, School of Chemistry and Molecular Biosciences, Queensland 4072, Australia; \\ ${ }^{2}$ The J. Craig Venter Institute, Rockville, Maryland 20850, USA
}

\begin{abstract}
The mitochondrial ( $\mathrm{mt}$ ) genomes of animals typically consist of a single circular chromosome that is $\sim 16-\mathrm{kb}$ long and has 37 genes. Our analyses of the sequence reads from the Human Body Louse Genome Project and the patterns of gel electrophoresis and Southern hybridization revealed a novel type of $\mathrm{mt}$ genome in the sucking louse, Pediculus humanus. Instead of having all $\mathrm{mt}$ genes on a single chromosome, the $37 \mathrm{mt}$ genes of this louse are on 18 minicircular chromosomes. Each minicircular chromosome is 3-4 kb long and has one to three genes. Minicircular mt chromosomes are also present in the four other species of sucking lice that we investigated, but not in chewing lice nor in the Psocoptera, to which sucking lice are most closely related. We also report unequivocal evidence for recombination between minicircular $\mathrm{mt}$ chromosomes in $P$. humanus and for sequence variation in $\mathrm{mt}$ genes generated by recombination. The advantages of a fragmented $\mathrm{mt}$ genome, if any, are currently unknown. Fragmentation of $\mathrm{mt}$ genome, however, has coevolved with blood feeding in the sucking lice. It will be of interest to explore whether or not life history features are associated with the evolution of fragmented chromosomes.
\end{abstract}

[The nucleotide sequences of the minicircular mitochondrial chromosomes reported in this study have been submitted to GenBank (http://www.ncbi.nlm.nih.gov/Genbank/) under accession nos. EU219983-EU219995, F]499473-F]499490, and F]514591-F]514599.]

\begin{abstract}
Changes in the number and structure of chromosomes have long been thought to play a role in the evolution of organisms (Williams 1966; White 1973, 1978), although the mechanisms involved are not well understood (Sites and Moritz 1987; Rieseberg 2001). It is well known that eukaryotes and prokaryotes have very different numbers and structures of chromosomes. Eukaryotes have two types of chromosomes: one in nuclei and the other in mitochondria and chloroplasts. The nuclear chromosomes of eukaryotes are linear and vary greatly in number, even among species that are closely related. At one extreme, the jumper ant, Myrmecia pilosula, has only one pair of nuclear chromosomes; at the other extreme, the Adder's Tongue fern, Ophioglossum reticulatum, has 630 pairs of nuclear chromosomes. The Indian muntjac deer, Muntiacus muntjak, has three pairs of nuclear chromosomes, whereas the Chinese muntjac deer, Muntiacus reevesi, has 23 pairs of nuclear chromosomes (Wurster and Benirschke 1970). In contrast to eukaryotes, most prokaryotes have only one circular chromosome, but a number of bacteria have linear or multiple chromosomes (Jumas-Bilak et al. 1998; Prozorov 2008). The mitochondria and chloroplasts of eukaryotes evolved from endosymbiotic bacteria; thus, the chromosomes in these organelles have many characteristics of bacterial chromosomes (Gray 1999). The mitochondrial and chloroplast chromosomes of most eukaryotes are circular and most eukaryotes have only one mitochondrial and/or chloroplast chromosome (Gray 1999). Linear and multiple mitochondrial and chloroplast chromosomes, how-
\end{abstract}

\footnotetext{
${ }^{3}$ These authors contributed equally to this work.

${ }^{4}$ Corresponding author.

E-mail r.shao@uq.edu.au; fax 61-7-33654699.

Article published online before print. Article and publication date are at http://www.genome.org/cgi/doi/10.1101/gr.083188.108.
}

ever, have been found in protists (including algae, ciliates, flagellates, slime molds, and ichthyosporeans), oomycetous fungi, yeasts, and cnidarians (Nosek et al. 1998; Zhang et al. 1999; Burger et al. 2003). In animals (Metazoa), the mitochondrial chromosomes are typically circular, $\sim 16$-kb long and have 37 genes (Boore 1999; Fig. 1A).

Lice (order Phthiraptera; class Insecta) are obligate ectoparasites of birds and mammals. The Phthiraptera has four suborders: Anoplura, Amblycera, Ischnocera, and Rhyncophthirina (Barker 1994). The Anoplura are sucking lice, whereas the other three suborders are chewing lice. Sucking lice parasitize placental mammals (Durden and Musser 1994) and feed exclusively on blood. Chewing lice infest birds and mammals and feed primarily on epidermal features, such as hairs and feathers (Price et al. 2003). The mitochondrial $(\mathrm{mt})$ genomes of three chewing lice have been sequenced entirely: a wallaby louse, Heterodoxus macropus (Amblycera), a pigeon louse, Campanulotes bidentatus (Ischnocera), and a screamer louse, Bothriometopus macrocnemis (Ischnocera) (Shao et al. 2001b; Covacin et al. 2006; Cameron et al. 2007). Like most other animals, these three chewing lice have their $37 \mathrm{mt}$ genes on a single circular chromosome, 14,670-, 14,804-, and 15,564-bp long, respectively. Over several years we attempted, but were unable, to amplify the entire mt genomes of any sucking lice by either polymerase chain reaction (PCR) (Nelson et al. 1996) or rolling circle amplification (RCA) (Simison et al. 2006), although these techniques have successfully amplified the entire $\mathrm{mt}$ genomes of many animals. We suspected that the structure of $\mathrm{mt}$ genomes of sucking lice differed substantially from those of chewing lice and other animals. The Human Body Louse Genome Project allowed us to investigate this possibility.

In this study we report that the single mt chromosome typical of animals has evolved into 18 minichromosomes in the 

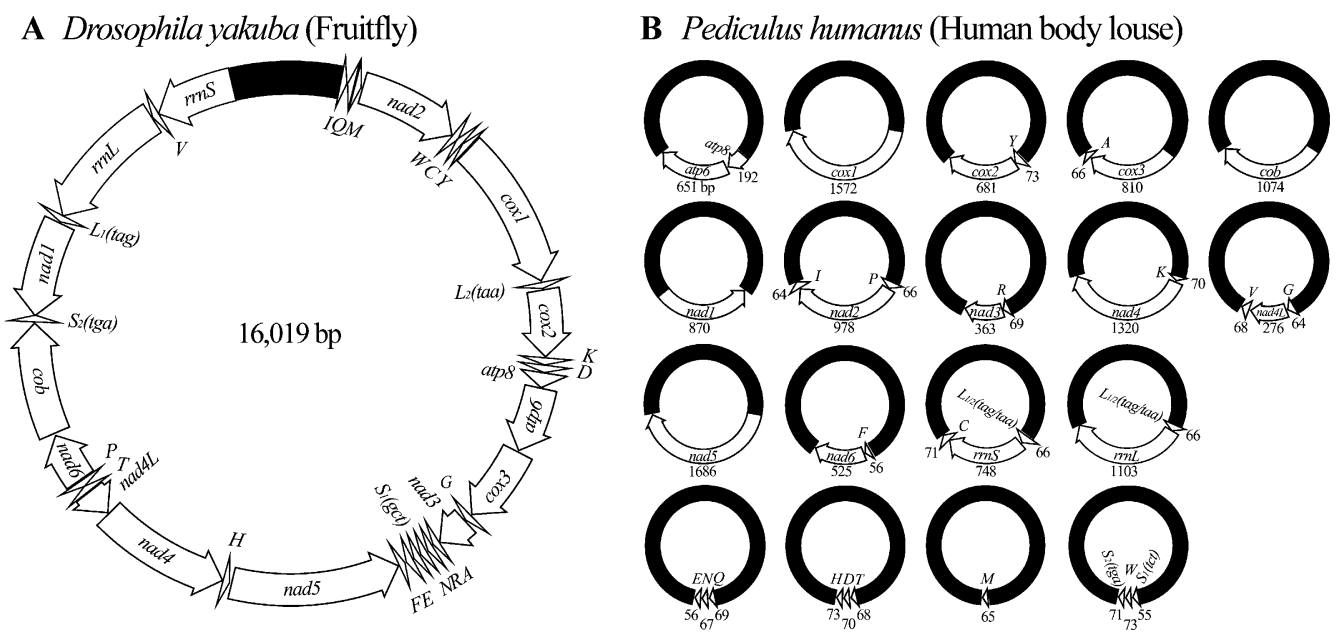

Figure 1. (A) The typical mitochondrial ( $\mathrm{mt}$ ) genome of animals, represented here by a fruitfly, Drosophila yakuba; $(B)$ the mt genome of the human body louse, Pediculus humanus. The $\mathrm{mt}$ genome of Drosophila yakuba consists of a single circular chromosome that is 16,019 -bp long and has $37 \mathrm{genes}$ (GenBank accession no. NC_001322). The mt genome of $P$. humanus, however, consists of 18 minicircular chromosomes; each minicircular chromosome is 3000-4000-bp long and has one to three genes. Genes are represented as boxes and are drawn to scale. The length of each gene of $P$. humanus is indicated near the box that represents the gene. Arrows indicate the direction of transcription. Protein-coding genes are abbreviated as atp6 and atp8 (for ATP synthase subunits 6 and 8), cox 1-3 (for cytochrome coxidase subunits 1 to 3), cob (for cytochrome $b$ ), and nad 1-6 and 4L (for NADH dehydrogenase subunits 1-6 and 4L). rrnL and $r r n S$ are for large and small rRNA subunits. tRNA genes are shown with the single-letter abbreviations of their corresponding amino acids. The noncoding regions are in black. The 18 minichromosomes of $P$. humanus are in alphabetical order according to the names of their protein-coding and rRNA genes; those with only tRNA genes are in the last row.

human body louse, Pediculus humanus (a sucking louse). This novel type of $\mathrm{mt}$ genome is present in the other sucking lice that we investigated but not in chewing lice nor the Psocoptera, to which sucking lice are most closely related. We compared the structure of mt genomes and the life history of sucking lice with chewing lice and the Psocoptera. It appears that blood feeding has coevolved with minicircular $\mathrm{mt}$ chromosomes in the lineage leading to sucking lice. We also report evidence for frequent recombination between mt minichromosomes in P. humanus. Recombination between $\mathrm{mt}$ minichromosomes could increase sequence variation in $\mathrm{mt}$ genes, and increased sequence variation might have been an advantage to the ancestor of sucking lice when they were adapting to a new diet, blood, and new hosts, the eutherian mammals.

\section{Results}

The mt genome of the human body louse, $P$. humanus, consists of 18 minicircular chromosomes; each minicircular chromosome is $3-4 \mathrm{~kb}$ long and has one to three genes

The Human Body Louse Genome Project used a whole-genome shotgun sequencing strategy and generated 1,480,551 nt sequence reads from the nuclear genome and the $\mathrm{mt}$ genome of $P$. humanus, and the genomes of the endosymbiotic bacteria of this louse (Pittendrigh et al. 2006). Notably, 99.84\% $(37,084)$ of the 37,144 sequence reads that contain mt genes are from the library that has inserts of $4 \pm 0.8 \mathrm{~kb}$, although this library accounts for only $53.12 \%$ of the total sequence reads. The extremely biased distribution of the sequence reads that contain $\mathrm{mt}$ genes toward the $4 \pm$ 0.8 -kb library indicates that the mt genome of $P$. humanus consists of multiple chromosomes that are $4 \pm 0.8 \mathrm{~kb}$ in size, rather than a single chromosome that is $\sim 16 \mathrm{~kb}$. The presence of multiple $\mathrm{mt}$ chromosomes was confirmed by the assembly of sequence reads and by our analyses of the patterns of gel electrophoresis and Southern hybridization (see below).

Of the 37,144 sequence reads that had $\mathrm{mt}$ genes, 36,615 were assembled into 18 contigs. Each contig has a different mt gene, or a cluster of two or three mt genes, flanked by noncoding sequences. These genes and gene clusters range from 65 (trnM gene) to $1686 \mathrm{bp}$ (nad5 gene) (Fig. 1B). Together, the 18 contigs contain all of the $37 \mathrm{mt}$ genes typical of animals. The structure of these contigs indicates that the mt genome of $P$. humanus consists of 18 minichromosomes; each of these minichromosomes has one to three genes (Fig. 1B).

To confirm the sizes of the mt minichromosomes of $P$. humanus and to find out whether these minichromosomes were circular or linear, we examined the patterns of agarose gel electrophoresis and Southern hybridization of undigested and ApaIdigested mtDNA of $P$. humanus. Each of the 18 contigs (above) has one, and only one, ApaI cut site $\left(\mathrm{G}_{\wedge} \mathrm{GGCC}{ }^{\vee} \mathrm{C}\right)$ near the 3 '-end of each gene or gene cluster. If the mt minichromosomes of $P$. humanus are $4 \pm 0.8 \mathrm{~kb}$ in size and are circular, then the ApaI digestion of minichromosomes will generate DNA fragments of $4 \pm$ $0.8 \mathrm{~kb}$. On the other hand, if the mt minichromosomes are $4 \pm 0.8$ $\mathrm{kb}$ in size and are linear, then the ApaI digestion of minichromosomes will generate DNA fragments of two different sizes; each size will be smaller than $4 \pm 0.8 \mathrm{~kb}$ and the sum of the two sizes will be $4 \pm 0.8 \mathrm{~kb}$. If the mt minichromosomes are $4 \pm 0.8 \mathrm{~kb}$ in size and are in both circular and linear configurations, then the ApaI digestion of minichromosomes will generate DNA fragments of three different sizes: one size will be $4 \pm 0.8 \mathrm{~kb}$, whereas the sum of the other two sizes will be $4 \pm 0.8 \mathrm{~kb}$.

Our agarose gel electrophoresis showed that the undigested mtDNA of $P$. humanus was a smear with a predominant size of 6-9 $\mathrm{kb}$, whereas the ApaI-digested mtDNA of $P$. humanus was a block of fragments that vary in size from 3 to $4 \mathrm{~kb}$ (Fig. 2, lanes 7,8, left). The agarose gel electrophoresis results were confirmed by Southern 


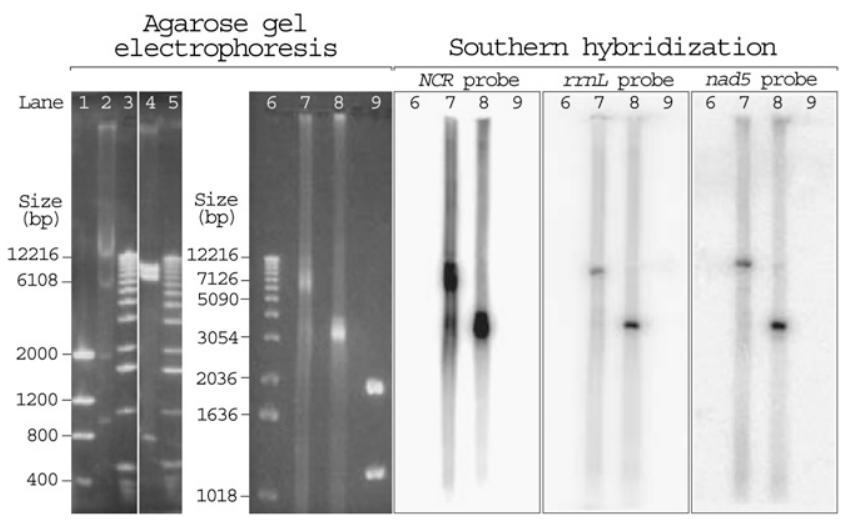

Figure 2. Agarose gel electrophoresis (left) and Southern hybridization (right) of the mitochondrial (mt) DNA of a fruitfly, D. melanogaster; a mouse, Mus musculus; and the human body louse, P. humanus. (Lanes 1,9) Two microliters low mass ladder DNA marker (Invitrogen); (lane 2) EcoRI-digested mtDNA extracted from $182 \mathrm{mg}$ of fruitflies; (lanes $3,5,6) 2$ $\mu \mathrm{L}$ DNA molecular weight marker X (Roche); (lane 4) BamHI-digested mtDNA extracted from $36 \mathrm{mg}$ of mouse liver tissues; (lane 7) undigested mtDNA extracted from $212 \mathrm{mg}$ of human body lice; (lane 8) Apaldigested mtDNA extracted from $212 \mathrm{mg}$ of human body lice. The fruitfly and the mouse were experimental controls. As expected, the 19,517-bp $\mathrm{mt}$ chromosome of the fruitfly was cut into four fragments by EcoRI: $\sim 12,000, \sim 5500, \sim 1700$, and $\sim 900$ bp (lane 2); and the 16,300-bp mt chromosome of the mouse was cut into three fragments by BamHI: $\sim 8600, \sim 7000$, and $\sim 700$ bp (lane 4 ). The undigested mtDNA of $P$. humanus migrated as a smear with a predominant size of 6000-9000 bp (lane 7 ), whereas the Apal-digested mtDNA of $P$. humanus appeared as a block that ranges from 3000 to $4000 \mathrm{bp}$ (lane 8 ).

hybridization with three probes: (1) an NCR probe, which was designed from a segment of the noncoding region that was highly conserved among all of the $18 \mathrm{mt}$ minichromosomes (see below); (2) an $r r n L$ probe, which was specific to the mt minichromosomes that contained the $r m L$ gene; and (3) an nad5 probe, which was specific to the mt minichromosomes that contained the nad5 gene (Fig. 2, right). The patterns of agarose gel electrophoresis and Southern hybridization of undigested and ApaI-digested mtDNA of $P$. humanus can only be explained by the $18 \mathrm{mt}$ minichromosomes of $P$. humanus being circles that vary in size from 3 to $4 \mathrm{~kb}$. The variation in size among the 18 minichromosomes is due to the variation in the size of both the coding regions (see above) and the noncoding regions (see below). The smear from 6 to $9 \mathrm{~kb}$ in the undigested mtDNA of $P$. humanus (Fig. 2, lane 7) is most likely nicked circular DNA, 3-4 kb in size. This apparent size difference between undigested and digested circular DNA was also observed in our control, the circular plasmids of similar size (data not shown).

From the evidence above, we conclude that the mt genome of $P$. humanus consists of 18 minicircular chromosomes that are $3-4 \mathrm{~kb}$ in size (Fig. 1B). Each minicircular chromosome has a coding region and a noncoding region. Five of the 18 minicircular chromosomes have only one gene: $c o b, c o x 1, \operatorname{nad} 1, \operatorname{nad} 5$, and $\operatorname{trn} M$, respectively. Seven minicircular chromosomes have two genes: atp8-atp6, trnYcox2, cox3-trnA, trnR-nad3, trnK-nad4, trnF-nad6, and trnL-rrnL. The other six minicircular chromosomes have three genes: trnP-nad2trnI, trnG-nad4L-trnV, trnL-rrnS-trnC, trnQ-trnN-trnE, trnT-trnD-trnH, and $t m S_{1}$-trnW-trnS $S_{2}$ (Note: hyphens link neighboring genes on the same minicircular chromosome). Where there are two or three genes in a minichromosome, these genes are on the same strand and are either immediately next to one another, or overlap by 1-2 $\mathrm{bp}$, or have 1-4 bp of noncoding sequences in between.
The noncoding regions of the minicircular mitochondrial chromosomes of $P$. humanus are highly polymorphic but share three blocks of highly conserved nucleotide sequence

To obtain full-length sequences of noncoding regions, we sequenced nine plasmid clones entirely: three clones with inserts of the cox 1 minicircular chromosome, two clones with inserts of the nad4 minicircular chromosome, and four clones with inserts of the nad5 minicircular chromosome (Fig. 3). The sequence identity among the noncoding regions of different clones of the same type of minicircular chromosome is higher (92\%-97\%) than that among the noncoding regions of different minicircular chromosomes (77\%-87\%); an unrooted neighbor-joining $(\mathrm{NJ})$ tree has all of the noncoding regions of the same minicircular chromosomes together (Fig. 4). The noncoding regions are highly polymorphic, even among clones of the same minicircular chromosome (Fig. 3). These polymorphisms are mainly within repetitive motifs that vary in sequence, length (11-373 bp) and copy number (2-7). The nine plasmid clones that we sequenced were unlikely from the same individual louse because the libraries in the Human Body Louse Genome Project were constructed from hundreds of lice (Pittendrigh et al. 2006). So, the polymorphisms in the noncoding regions we revealed in this study are more likely among different individuals of $P$. humanus than within an individual louse. The noncoding regions of the minicircular chromosomes, on the other hand, have three blocks of highly conserved sequences (Fig. 3). A block of sequence at the start and another at the end of the noncoding regions, 523- and 101-bp long, respectively, have $90 \%$ and $99 \%$ nucleotide identity, respectively. An internal block (302 bp) is almost perfectly conserved and part of this block has the potential to form a stable stem loop (Fig. 5). Stem loops are the initiation sites of replication and transcription of the $\mathrm{mt}$ genomes of several animals (Wong and Clayton 1985; Clayton 1991; L'Abbe et al. 1991).

Compared with the noncoding regions, the coding regions of the minicircular chromosomes are much less polymorphic. We analyzed the sequence variation in five mitochondrial genes: three protein-coding genes, atp 8 , cox1, and nad1, one rRNA gene, rrnS, and one tRNA gene, trnM. We found a single nucleotide polymorphism (SNP) in atp8, seven SNPs in cox1, six SNPs in nad1, five SNPs in $r r n S$, but no SNPs in trnM (Table 1). The numbers of SNPs at the first, second, and third codon positions of the three proteincoding genes are almost equal. This is unexpected, because SNPs at the first and second codon positions may cause changes in amino acid sequence more frequently than SNPs at the third codon position. It is possible that some of the SNPs in the three proteincoding genes, especially those that appear only once in sequence reads (Table 1), occurred recently and thus have not been eliminated by selection. Alternatively, the amino acid changes caused by SNPs at the first and the second codon position may have only minor effects on the function of the proteins encoded by these genes.

\section{Mitochondrial minicircular chromosomes are present in other sucking lice but not in chewing lice and the Psocoptera}

We tested by PCR and sequenced part of the mt genomes of the human head louse, Pediculus capitis; the human crab louse, Pthirus pubis; the chimpanzee louse, Pediculus schaeffi; and the langur louse, Pedicinus ancoratus. We found that at least 12 minicircular $\mathrm{mt}$ chromosomes were present in the human head louse, at least nine in the human crab louse, at least five in the chimpanzee louse, and at least one in the langur louse (Fig. 6). These lice 


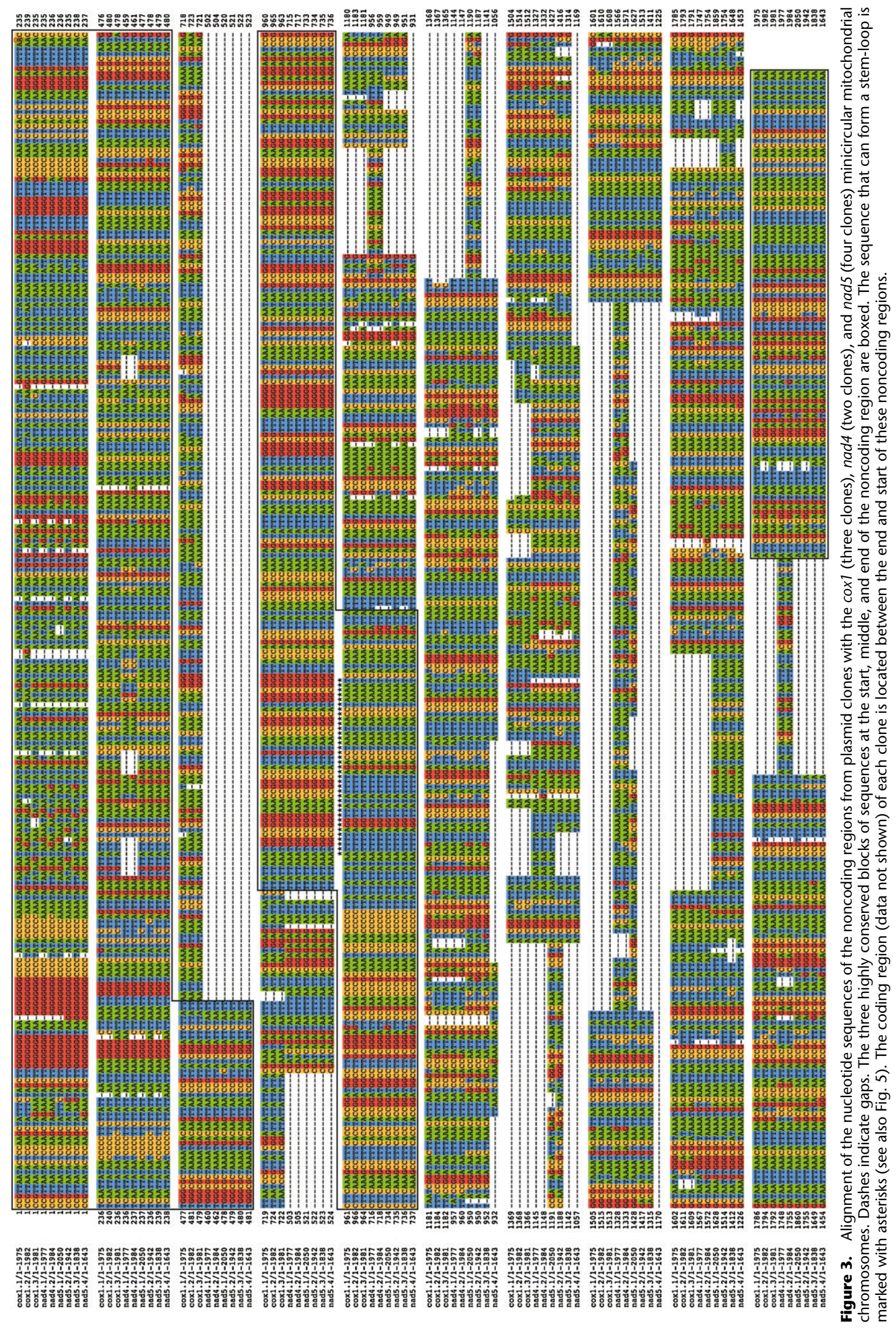




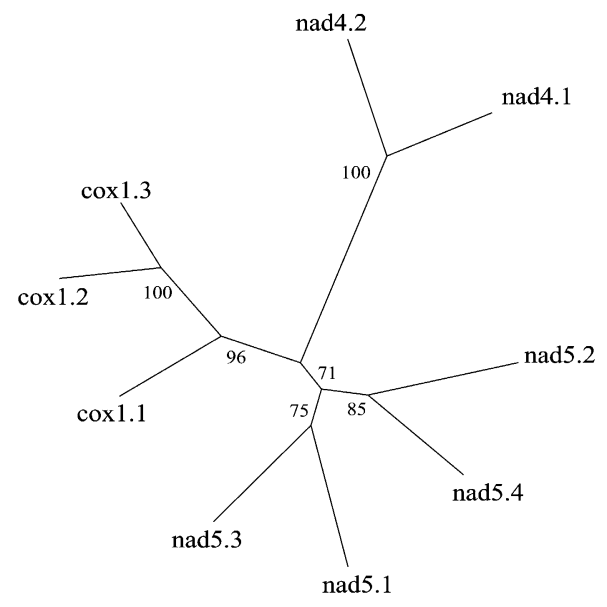

0.01 substitutions/site

Figure 4. An unrooted neighbor-joining $(\mathrm{NJ})$ tree inferred from the nucleotide sequences of the noncoding regions of $\operatorname{cox} 1$, nad4, and nad5 minicircular mitochondrial chromosomes (see also Fig. 3). Gaps in sequence alignment were excluded. Bootstrap support in percentage (1000 replicates) is shown near each branch. Noncoding regions (e.g., cox1.1) are named after the minicircular chromosome and the plasmid clone number.

represent all three of the families of sucking lice (suborder Anoplura) of primates: Pediculidae, Pthiridae, and Pedicinidae (Durden and Musser 1994). Thus, minicircular mt chromosomes likely evolved in or before the most recent common ancestor of the sucking lice of primates, which apparently lived $\sim 22.5$ Mya (Reed et al. 2004).

Sucking lice are most closely related to chewing lice and the Psocoptera (Barker 1994; Johnson et al. 2004). The mt genomes of three species of chewing lice and one species of the Psocoptera, i.e., a wallaby louse, Heterodoxus macropus (suborder Amblycera); a pigeon louse, Campanulotes bidentatus (suborder Ischnocera); a screamer louse, B. macrocnemis (Ischnocera); and Lepidopsocid sp. (Psocoptera), have been sequenced entirely (Shao et al. 2001b, 2003; Covacin et al. 2006; Cameron et al. 2007). Furthermore, seven species of chewing lice and two species of Psocoptera have been sequenced partially (Shao et al. 2001a, b; Covacin et al. 2006; Cameron et al. 2007). There is no evidence for minicircular $\mathrm{mt}$ chromosomes in any of these chewing lice nor the Psocoptera.

\section{Discussion}

Sucking lice are the first group of animals known in which fragmented $\mathrm{mt}$ chromosomes likely replaced the typical $\mathrm{mt}$ chromosomes

The multiple mt minicircular chromosomes of the sucking lice we reported in this study evolved, with little doubt, from a single circular mt chromosome typical of animals. Chromosomal fragmentation has been found previously in the nuclear genomes of ciliates (Prescott 1994), the chloroplast genomes of dinoflagaellates (Zhang et al. 1999), and the mitochondrial genomes of an ichthyosporean, Amoebidium parasiticum (Burger et al. 2003), a diplonemid flagellate, Diplonema papillatum (Marande et al. 2005) and a mesozoan, Dicyema misakiense (Watanabe et al. 1999). The nature of the chromosomal fragmentation in these eukar- yotes, however, differs in: (1) the form (i.e., linear or circular), the number (from less than 10 to more than 24,000), and the replication capability of the fragmented chromosomes; (2) whether or not the genes on each fragmented chromosome are full length or partial; and (3) the presence or absence of the typical chromosomes. The ciliates have two sets of nuclear chromosomes; one set is in the germ-line micronucleus and has the typical linear structure with many genes on each chromosome, whereas the other set is in the somatic macronucleus and has hundreds or even thousands of linear, gene-sized chromosomes (Prescott 1994). The genes on the fragmented chromosomes of the ciliates are full length and are apparently able to replicate. The dinoflagaellates have up to 14 minicircular chloroplast chromosomes; each has one or a few full-length genes and is likely able to replicate (Zhang et al. 1999). There is no evidence for typical chloroplast chromosomes in the dinoflagaellates. The diplonemid flagellate, $D$. papillatum, may have $\sim 56$ minicircular $\mathrm{mt}$ chromosomes; each has only part (<300 bp) of a gene (Marande et al. 2005). There is no evidence for typical $\mathrm{mt}$ chromosomes in $D$. papillatum, and it is not clear whether the fragmented chromosomes of this flagellate are able to replicate or not. Three mt genes ( $\operatorname{cox} 1, \operatorname{cox} 2$, and $\operatorname{cox} 3)$ of the mesozoan, D. misakiense, were found in three separate DNA minicircles (Watanabe et al. 1999). These DNA minicircles, however, have apparently been generated from typical mt chromosomes, and do not appear to be able to replicate (Awata et al. 2005). Each DNA minicircle of D. misakiense has a few full-length $\mathrm{mt}$ genes. In the present study, we did not find any evidence for typical $\mathrm{mt}$ chromosomes in P. humanus. The sucking lice, thus, are the second lineage of animals known (in addition to dicyemids) to have fragmented $\mathrm{mt}$ chromosomes and, further, the only lineage of animals known in which fragmented $\mathrm{mt}$ chromosomes apparently replaced the typical $\mathrm{mt}$ chromosomes.

\section{Life history may be associated with the evolution of fragmented chromosomes}

According to a model by Smith and Szathmary (1993), there is positive selection for genes to be linked together on a chromosome rather than being separated from one another. Having genes linked together on a chromosome, such as the typical mt chromosome of animals, ensures that each daughter organelle/cell will receive all of the genes on the chromosome and the ratios of these genes are not changed after segregation. Although chromosomes with many genes may take longer to replicate than chromosomes with one or a few genes, this disadvantage may be less than the advantage of having genes linked together on one chromosome. The model of Smith and Szathmary (1993) seems to explain well

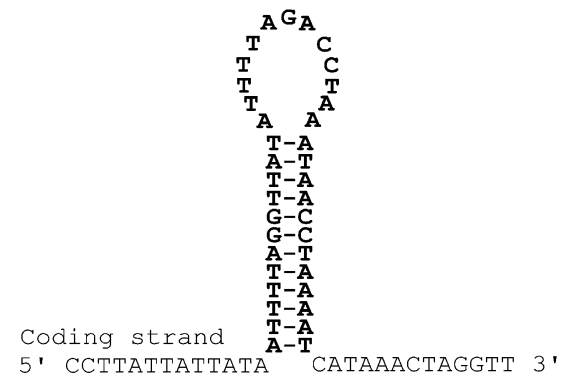

Figure 5. A putative stem-loop in the 302-bp highly conserved segment of the noncoding regions of the minicircular mitochondrial chromosomes of the human body louse, $P$. humanus. 
Table 1. Nucleotide polymorphism among sequence reads in five mitochondrial genes of the human body louse, $P$. humanus

\begin{tabular}{|c|c|c|c|c|c|}
\hline Gene & $\begin{array}{l}\text { Length } \\
\text { (bp) }\end{array}$ & $\begin{array}{l}\text { Polymorphic } \\
\text { nucleotide site }\end{array}$ & $\begin{array}{c}\text { Sequence } \\
\text { polymorphism }\end{array}$ & $\begin{array}{l}\text { Codon } \\
\text { position }\end{array}$ & $\begin{array}{l}\text { Amino acid } \\
\text { polymorphism }\end{array}$ \\
\hline atp8 & 192 & 128 & $\mathrm{~T}(323)^{\mathrm{a}}, \mathrm{C}(30)$ & Second & L, S \\
\hline \multirow[t]{7}{*}{$\operatorname{cox} 1$} & 1572 & 5 & $\mathrm{~T}(356), \mathrm{C}(1)$ & Second & $\mathrm{M}, \mathrm{T}$ \\
\hline & & 81 & $C(387), T(35)$ & Third & No \\
\hline & & 434 & $G(383), A(1)$ & Second & $G, D$ \\
\hline & & 1145 & $\mathrm{~T}(619), \mathrm{C}(1)$ & Second & $\mathrm{V}, \mathrm{A}$ \\
\hline & & 1425 & C (578), C deletion (1) & Third & Frame shift \\
\hline & & 1515 & $\mathrm{~T}(454), \mathrm{C}(1)$ & Third & No \\
\hline & & 1555 & $A(380), T(1)$ & First & $\mathrm{T}, \mathrm{S}$ \\
\hline \multirow[t]{6}{*}{ nad1 } & 870 & 162 & $\mathrm{~T}(672), \mathrm{C}(5)$ & Third & No \\
\hline & & 181 & $A(669), G(1)$ & First & $\mathrm{T}, \mathrm{A}$ \\
\hline & & 231 & $\mathrm{~T}(656), \mathrm{A}(3)$ & Third & No \\
\hline & & 460 & $G(471), A(5)$ & First & $A, T$ \\
\hline & & 793 & $\mathrm{C}(466), \mathrm{T}(1)$ & First & $\mathrm{P}, \mathrm{S}$ \\
\hline & & 824 & $\mathrm{~T}(453), A(1)$ & Second & $\mathrm{F}, \mathrm{Y}$ \\
\hline \multirow[t]{5}{*}{$r r n S$} & 748 & 72 & $C(950), T(1)$ & N.A. & N.A. \\
\hline & & 206 & $A(776), G(54)$ & N.A. & N.A. \\
\hline & & 682 & $C(1374), G(1)$ & N.A. & N.A. \\
\hline & & 693 & $\mathrm{C}(1353), \mathrm{T}(2)$ & N.A. & N.A. \\
\hline & & 724 & $\mathrm{~T}(1293), \mathrm{A}(1)$ & N.A. & N.A. \\
\hline $\operatorname{trnM}$ & 65 & No & No (1119) & N.A. & N.A. \\
\hline
\end{tabular}

${ }^{\mathrm{a} N u m b e r s ~ i n ~ p a r e n t h e s e s ~ i n d i c a t e ~ t h e ~ n u m b e r ~ o f ~ s e q u e n c e ~ r e a d s ~ t h a t ~ h a v e ~ t h e ~ n u c l e o t i d e . ~}$

why the nuclear and organelle chromosomes of the vast majority of the eukaryotes whose chromosomes have been studied have many genes, whereas only a small number of eukaryotes (listed above) have chromosomes with one or a few genes.

If chromosomes with many genes were selected for, why did the chromosomes of the exceptional eukaryotes we listed above become fragmented and thus have only one or a few genes? What drove the evolution of fragmentation of chromosomes in these eukaryotes? Chromosomes with one or a few genes may replicate faster than typical chromosomes that have many genes. Replication advantage alone, however, does not appear to be sufficient to lead to chromosomal fragmentation. Thus, other factors may be more important than replication advantage in driving the chromosomal fragmentation. In the case of sucking lice, the fragmented $\mathrm{mt}$ chromosomes have coevolved with blood feeding. Chewing lice feed primarily on the hairs and feathers of their mammal and bird hosts; the Psocoptera feed on algae, fungi, and fragments of plant and insect tissues. Sucking lice, however, feed exclusively on the blood of their mammalian hosts. It will be of interest to explore the relationship between these two derived features of sucking lice.

Did the fragmentation of mitochondrial chromosomes have a role in the evolution of sucking lice?

Changes in the number and structure of chromosomes have long been thought to play a role in the evolution of organisms (Williams 1966; White 1973, 1978). It is still not well understood, however, how chromosome changes may interact with organism evolution (Sites and Moritz 1987; Rieseberg 2001). Could mt chromosomal fragmentation have a role in the evolution of sucking lice? If yes, what could that role be? We note that several $\mathrm{mt}$ genes of $P$. humanus have stretches of identical sequences that are much longer than expected. Any two mt protein-coding and rRNA genes of an animal can be expected by chance to have identical sequences that are up to 16-bp long, and any two mt tRNA genes to have identical sequences that are up to 10-bp long (Table 2). Five pairs of $\mathrm{mt}$ genes of $P$. humanus, nad4 and nad5, rrnL and nad5, trnL $L_{1}$ and $t r n L_{2}$, trnR and $\operatorname{trn} G$, and $r r n L$ and nad2, however, have identical sequences that are $127,99,33,28$, and $26 \mathrm{bp}$, respectively. These are eight, six, three, three, and two times longer than expected. Why do so many $\mathrm{mt}$ genes of $P$. humanus, which are on different minichromosomes, have identical sequences that are much longer than expected? The only plausible explanation is that the minichromosomes of $P$. humanus recombine with each other and recombine often. Since increased chromosome numbers in nuclear genomes tend to cause increased genetic recombination (Qumsiyeh 1994), we propose that the recombination between minichromosomes is likely facilitated by the fact that the mt genome of $P$. humanus comprises 18 minichromosomes. The extreme sequence variation in the noncoding regions of the minicircular chromosomes of $P$. humanus is also consistent with our proposal of frequent recombination between minichromosomes. Mitochondrial minichromosomes may have been selected for during the evolution of sucking lice, possibly because recombination between minichromosomes increases the genetic variation in $\mathrm{mt}$

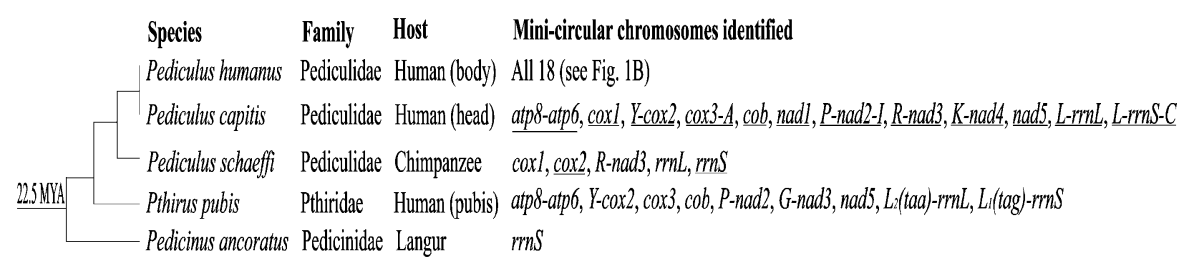

Figure 6. Evolution of minicircular mitochondrial $(\mathrm{mt})$ chromosomes in the sucking lice of primates. The phylogeny of the sucking lice of primates and the estimate of the date of their most recent common ancestor (22.5 Mya) are after Barker et al. (2003) and Reed et al. (2004). The preferred habitats of lice on humans (i.e., body, head, and pubis) are in parentheses. The 18 minicircular mt chromosomes of the human body louse were sequenced entirely; the minicircular $\mathrm{mt}$ chromosomes of other lice were partially sequenced or identified by PCR tests (underlined). Hyphens link neighboring genes on the same minicircular chromosome. 
Table 2. The longest stretches of identical sequence in five pairs of mitochondrial genes of the human body louse, $P$. humanus, and six other species of animals

\begin{tabular}{|c|c|c|c|c|c|c|c|c|}
\hline & & \multicolumn{7}{|c|}{ The longest stretches of identical sequence (bp) } \\
\hline \multicolumn{2}{|c|}{ Pairs of gene } & $P h^{\mathrm{a}}$ & $B m$ & $C b$ & $\mathrm{Hm}$ & $D y$ & $\mathrm{Ce}$ & Hs \\
\hline nad4 & nad5 & 127 & 13 & 15 & 15 & 16 & 14 & 11 \\
\hline$r r n L$ & nad5 & 99 & 12 & 14 & 13 & 15 & 16 & 10 \\
\hline $\operatorname{trn} L_{1}$ & $\operatorname{trnL} L_{2}$ & 33 & 7 & 6 & 7 & 10 & 6 & 6 \\
\hline $\operatorname{trnR}$ & $\operatorname{trn} G$ & 28 & 5 & 6 & 7 & 6 & 8 & 6 \\
\hline$r r n L$ & $\operatorname{nad} 2$ & 26 & 13 & 11 & 14 & 13 & 12 & 10 \\
\hline
\end{tabular}

aAbbreviations of species names: Ph, Pediculus humanus; Bm, Bothriometopus macrocnemis (screamer louse); $\mathrm{Cb}$, Campanulotes bidentatus (pigeon louse) $\mathrm{Hm}$, Heterodoxus macropus (wallaby louse); Dy, Drosophila yakuba (fruitfly); $\mathrm{Ce}$, Caenorhabditis elegans (roundworm); Hs, Homo sapiens (human).

genes. This might have been an advantage to the sucking lice when they were adapting to a new diet, blood, and new hosts, the eutherian mammals.

\section{How did a single typical mitochondrial chromosome fragment into many minichromosomes?}

It is unlikely that all of the minicircular $\mathrm{mt}$ chromosomes in a sucking louse were generated from a single "big bang" event that fragmented a typical $\mathrm{mt}$ chromosome into many minichromosomes. A "big bang" event would not generate multiple minicircular chromosomes that all have the sequences needed for replication and transcription, because there is only one set of such sequences in each typical $\mathrm{mt}$ chromosome (see Taanman 1999). Rather, the multiple minicircular mt chromosomes of the sucking lice were more likely generated from a series of events that involved excision and rejoining of fragments of $\mathrm{mt}$ chromosome over a long period of time. In each event, a fragment that contained the noncoding region and one or a few genes near the noncoding region had been excised from a typical $\mathrm{mt}$ chromosome. The two ends of this fragment apparently joined together to form a functional minicircular $\mathrm{mt}$ chromosome. If this new $\mathrm{mt}$ minicircular chromosome had a selective advantage over the typical $\mathrm{mt}$ chromosome (above), then the genes on this minicircular $\mathrm{mt}$ chromosome would eventually take over the function of their counterparts on the typical mt chromosome, and thus make their counterparts on the typical mt chromosome redundant. The deletion of the redundant genes from the typical mt chromosome would move other genes closer to the noncoding region. The next event of excision-and-rejoining would generate another new minicircular mt chromosome. Eventually, all of the genes on a typical mt chromosome would be on minicircular chromosomes.

In summary, we discovered that the single mt chromosome that is typical of animals has evolved into 18 minichromosomes in the human body louse, $P$. humanus. This novel type of $\mathrm{mt}$ chromosome is also present in the other sucking lice whose $\mathrm{mt}$ genomes have been studied, but not in chewing lice nor the Psocoptera. Blood feeding appears to have coevolved with minicircular mt chromosomes in sucking lice. Whether this is a causeeffect association or chance association remains to be seen. Having multiple mt chromosomes may facilitate recombination between minichromosomes in sucking lice, and thus increases sequence variation in $\mathrm{mt}$ genes. Increased sequence variation in $\mathrm{mt}$ genes may have been an advantage to the sucking lice when they were adapting to a new diet, blood, and new hosts, the eutherian mammals. It remains to be elucidated, however, how changes in life history traits, such as feeding style, may interact with changes in mt genomic structure.

\section{Methods}

\section{Assembly of the mitochondrial genome of the human body} louse, $P$. humanus

Initial shotgun assembly of the sequence reads from the Human Body Louse Genome Project yielded six 3500-bp contigs that contained seven $\mathrm{mt}$ genes of $P$. humanus, whose sequences were in GenBank (cob, cox1, cox3-trnA, nad4, rrnL, and rrnS). These six contigs could not be linked to each other by paired sequence reads from the same plasmid clones; this was unexpected. We inspected these contigs and found two blocks of highly conserved noncoding sequences that flanked the coding sequence of each contig. These two blocks are 523- and 101-bp long and share 90\% and $99 \%$ nucleotide identity, respectively (Fig. 3). These conserved noncoding sequences were used subsequently to identify, by Mega BLAST (Zhang et al. 2000), 37,144 sequence reads that contained the mt genes of $P$. humanus. Assembly of these sequence reads yielded an additional 12 contigs that contained the other $30 \mathrm{mt}$ genes of $P$. humanus. The 18 contigs, together, have all of the 37 genes that are found commonly in the mt genomes of animals (Fig. 1A). The average sequence coverage for the coding regions of the 18 contigs is $916 \times$, and ranges from $434 \times$ (nad5) to $1773 \times$ (trnL/rrnL).

\section{Isolation, digestion, and hybridization of mitochondrial DNA}

The mtDNAs of the fruitfly, Drosophila melanogaster (Oregon strain); the mouse, Mus musculus (Quackenbush strain); and the human body louse, P. humanus (Orlando strain) were isolated with an alkaline lysis method (Tamura and Aotsuka 1988) and digested with EcoRI, BamHI, and ApaI (Roche), respectively. The mt genomes of M. musculus and D. melanogaster have been sequenced entirely (GenBank accession nos. DQ874614 and U37541) and were used as experimental controls. The mtDNAs were resolved by agarose gel $(0.9 \%)$ electrophoresis. The gel was stained with ethidium bromide, run for $1 \mathrm{~h}$ at $100 \mathrm{~V}$ and $60 \mathrm{~mA}$, visualized with a UV transilluminator, and then photographed. The mtDNA of $P$. humanus on the agarose gel was transferred to three nylon membranes and hybridized with NCR, $r r n L$, and nad5 probes, respectively. The NCR probe was amplified by PCR from the 302-bp internal segment of the noncoding region that is almost perfectly conserved among all of the 18 minicircular mt chromosomes of $P$. humanus. The $r r n L$ probe was amplified by PCR from a section of $r r n L$ (nt 616-1064) and was specific to the $r r n L$ minicircular $\mathrm{mt}$ chromosome. The nad 5 probe was amplified by PCR from a section of nad5 (nt 1226-1453) and was specific to the nad5 minicircular mt chromosome. The probes were labeled with Megaprime DNA Labeling System (Amersham) and dCTP $\left[\alpha-{ }^{32}\right.$ P]EasyTide Lead (PerkinElmer) and were hybridized with the DNA fixed on the nylon membranes for $16 \mathrm{~h}$. Unincorporated probes were then washed off. The nylon membranes were exposed to phosphorstorage screens for $12 \mathrm{~h}$ and hybridization images were taken with a Typhoon 9400 scanner.

\section{PCR amplification and sequencing of mitochondrial genomes}

Total DNA was extracted with the DNeasy Tissue Kit (QIAGEN) from: (1) the human head louse, Pediculus capitis, from Brisbane, Australia; (2) the human crab louse, Pthirus pubis, from Brisbane, 
Australia; (3) the chimpanzee louse, Pediculus schaeffi, from the Tacugama Chimpanzee Sanctuary, Sierra Leone; and (4) the langur louse, Pedicinus ancoratus, from the Cuc Phuong National Park, Vietnam. The sequences of the genes on the 18 minicircular $\mathrm{mt}$ chromosomes of the human body louse, P. humanus, were aligned with the sequences of their counterpart genes in the wallaby louse, H. macropus (Shao et al. 2001b), and the pigeon louse, C. bidentatus (Covacin et al. 2006). The two most conserved regions in the gene/ gene cluster of each minicircular mt chromosome of the human body louse were identified, and two primers, one forward and one reverse, were designed from each of these two regions. In total, 72 primers were designed from the 18 minicircular mt chromosomes of the human body louse. The total DNA and these primers were used in PCR tests to discover whether or not any of the 18 minicircular $\mathrm{mt}$ chromosomes that occurred in the human body louse were present in other sucking lice.

Two PCRs were set up to test for the presence of each minicircular mt chromosome in a species of louse: One PCR targeted a small section, 200-500 bp, of the coding region of the minicircular chromosome, whereas the other PCR targeted the rest of the minicircular chromosome, $2500-3100 \mathrm{bp}$. If both PCRs produce amplicons of expected sizes, then, and only then, the minicircular chromosome was concluded to be present. Otherwise, conclusions could not be drawn about the presence or absence of that minicircular chromosome. To ensure the reliability of PCR tests, both positive and negative controls were executed with each PCR test. Further, 13 of the 27 minicircular mt chromosomes identified by PCR tests in the human head louse, the human crab louse, the chimpanzee louse, and the langur louse were confirmed by sequencing their corresponding PCR amplicons (Fig. 6).

Elongase Enzyme Mix (GIBCO) and Takara La Taq (Takara) were used in PCR amplification, following the instructions of the manufacturers. PCR amplicons were checked by agarose gel (1\%) electrophoresis. The sizes of PCR amplicons were estimated by comparison with molecular markers. PCR amplicons used for sequencing were purified with Wizard SV Gel/PCR Clean-up System (Promega) and cloned with pGEM-T Easy Vector System (Promega). Sequencing reactions were with BigDye Terminator Kit (ABI) and resolved by capillary separation at the Australian Genome Research Facilities in Brisbane.

\section{Acknowledgments}

We thank Bao Tran and John Gill for transposon-mediated sequencing of plasmid clones; Natalie Leo, Cath Covacin, Mike Cranfield, Asami Kabasawa, Rosa Garriga, Margaret Mobbs, Tilo Nadler, Cynthia Pollard, and Chris Whittier for louse samples; Markus Riegler for fly samples; and Maryam Ashrafi and Michael Moore for mouse samples: We thank Wen Jun Liu, Yvette Emmanuel, Carl Morrow, and James Fraser for help with Southern hybridization. We also thank Nick Campbell, and three reviewers for comments that greatly improved this manuscript. This research was partly funded by an Australian Postdoctoral Fellowship from the Australian Research Council and an Early Career Researcher grant from The University of Queensland to R.S.

\section{References}

Awata, H., Noto, T., and Endoh, H. 2005. Differentiation of somatic mitochondria and the structural changes in mtDNA during development of the dicyemid Dicyema japonicum (Mesozoa). Mol. Genet. Genomics 273: 441-449.

Barker, S.C. 1994. Phylogeny and classification, origins, and evolution of host associations of lice. Int. J. Parasitol. 24: 1285-1291.
Barker, S.C., Whiting, M., Johnson, K.P., and Murrell, A. 2003. Phylogeny of the lice (Insecta, Phthiraptera) inferred from small subunit rRNA. Zool. Scr. 32: 407-414.

Boore, J.L. 1999. Animal mitochondrial genomes. Nucleic Acids Res. 27: 1767-1780.

Burger, G., Forget, L., Zhu, Y., Gray, M.W., and Lang, B.F. 2003. Unique mitochondrial genome architecture in unicellular relatives of animals. Proc. Natl. Acad. Sci. 100: 892-897.

Cameron, S.L., Johnson, K.P., and Whiting, M.F. 2007. The mitochondrial genome of the screamer louse Bothriometopus (Phthiraptera: Ischnocera): Effects of extensive gene rearrangements on the evolution of the genome. J. Mol. Evol. 65: 589-604.

Clayton, D.A. 1991. Replication and transcription of vertebrate mitochondrial DNA. Annu. Rev. Cell Biol. 7: 453-478.

Covacin, C., Shao, R., Cameron, S., and Barker, S.C. 2006. Extraordinary number of gene rearrangements in the mitochondrial genomes of lice (Phthiraptera: Insecta). Insect Mol. Biol. 15: 63-68.

Durden, L.A. and Musser, G.G. 1994. The sucking lice (Insecta, Anoplura) of the world -a taxonomic checklist with records of mammalian hosts and geographical distributions. Bull. Am. Mus. Nat. Hist. 218: 1-90.

Gray, M.W. 1999. Evolution of organellar genomes. Curr. Opin. Genet. Dev. 9: 678-687.

Johnson, K.P., Yoshizawa, K., and Smith, V.S. 2004. Multiple origins of parasitism in lice. Proc. Biol. Sci. 271: 1771-1776.

Jumas-Bilak, E., Michaux-Charachon, S., Bourg, G., Ramuz, M., and Allardet-Servent, A. 1998. Unconventional genomic organization in the alpha subgroup of the Proteobacteria. J. Bacteriol. 180: 2749-2755.

L'Abbe, D., Duhaime, J.F., Lang, B.F., and Morais, R. 1991. The transcription of DNA in chicken mitochondria initiates from one major bidirectional promoter. J. Biol. Chem. 266: 10844-10850.

Marande, W., Lukes, J., and Burger, G. 2005. Unique mitochondrial genome structure in diplonemids, the sister group of kinetoplastids. Eukaryot. Cell 4: 1137-1146.

Nelson, W.S., Prodohl, P.A., and Avise, J.C. 1996. Development and application of long-PCR for the assay of full-length animal mitochondrial DNA. Mol. Ecol. 5: 807-810.

Nosek, J., Tomaska, L., Fukuhara, H., Suyama, Y., and Kovac, L. 1998. Linear mitochondrial genomes: 30 Years down the line. Trends Genet. 14: 184 188.

Pittendrigh, B.R., Clark, J.M., Johnston, J.S., Lee, S.H., Romero-Severson, J., and Dasch, G.A. 2006. Sequencing of a new target genome: The Pediculus humanus humanus (Phthiraptera: Pediculidae) genome project. I. Med. Entomol. 43: 1103-1111.

Prescott, D.M. 1994. The DNA of ciliated protozoa. Microbiol. Rev. 58: 233 267.

Price, R.D., Hellenthal, R.A., Palma, R.L., Johnson, K.P., and Clayton, D.H. 2003. World checklist of chewing lice with host associations and keys to families and genera. In The chewing lice: World checklist and biological overview (eds. R.D. Price RD et al.). INHS special publication 24. Illinois Natural History Survey, IL.

Prozorov, A.A. 2008. Additional chromosomes in bacteria: Properties and origin. Microbiology 77: 385-394.

Qumsiyeh, M.B. 1994. Evolution of number and morphology of mammalian chromosomes. J. Hered. 85: 455-465.

Reed, D.L., Smith, V.S., Hammond, S.L., Rogers, A.R., and Clayton, D.H. 2004. Genetic analysis of lice supports direct contact between modern and archaic humans. PLoS Biol. 2: e340. doi: 10.1371/journal.pbio. 0020340.

Rieseberg, L.H. 2001. Chromosomal rearrangements and speciation. Trends Ecol. Evol. 16: 351-358.

Shao, R., Campbell, N.J., Schmidt, E.R., and Barker, S.C. 2001a. Increased rate of gene rearrangement in the mitochondrial genomes of three orders of hemipteroid insects. Mol. Biol. Evol. 18: 1828-1832.

Shao, R., Campbell, N.J.H., and Barker, S.C. 2001b. Numerous gene rearrangements in the mitochondrial genome of the wallaby louse, Heterodoxus macropus (Phthiraptera). Mol. Biol. Evol. 18: 858-865.

Shao, R., Dowton, M., Murrell, A., and Barker, S.C. 2003. Rates of gene rearrangement and nucleotide substitution are correlated in the mitochondrial genomes of insects. Mol. Biol. Evol. 20: 1612-1619.

Simison, W.B., Lindberg, D.R., and Boore, J.L. 2006. Rolling circle amplification of metazoan mitochondrial genomes. Mol. Phylogenet. Evol. 39: 562-567.

Sites, J.W. and Moritz, C. 1987. Chromosomal evolution and speciation revisited. Syst. Zool. 36: 153-174.

Smith, J.M. and Szathmary, E. 1993. The origin of chromosomes. 1. Selection for linkage. J. Theor. Biol. 164: 437-446.

Taanman, J.W. 1999. The mitochondrial genome: Structure, transcription, translation and replication. Biochim. Biophys. Acta 1410: 103-123.

Tamura, K. and Aotsuka, T. 1988. Rapid isolation method of animal mitochondrial DNA by the alkaline lysis procedure. Biochem. Genet. 26: 815-819. 
Shao et al.

Watanabe, K.I., Bessho, Y., Kawasaki, M., and Hori, H. 1999. Mitochondrial genes are found on minicircle DNA molecules in the mesozoan animal Dicyema. J. Mol. Biol. 286: 645-650.

White, M.J.D. 1973. Animal cytology and evolution. University Press, Cambridge, UK.

White, M.J.D. 1978. Modes of speciation. W.H. Freeman, San Francisco, CA.

Williams, G.C. 1966. Adaptation and natural selection: A critique of some current evolutionary thought. Princeton University Press, Princeton, NJ.

Wong, T.W. and Clayton, D.A. 1985. In vitro replication of human mitochondrial DNA: Accurate initiation at the origin of light-strand synthesis. Cell 42: 951-958.
Wurster, D.H. and Benirschke, K. 1970. Indian muntjac, Muntiacus muntjak: A deer with a low diploid chromosome number. Science 168: 1364-1366.

Zhang, Z., Green, B.R., and Cavalier-Smith, T. 1999. Single gene circles in dinoflagellate chloroplast genomes. Nature 400: 155-159.

Zhang, Z., Schwartz, S., Wagner, L., and Miller, W. 2000. A greedy algorithm for aligning DNA sequences. J. Comput. Biol. 7: 203-214.

Received July 9, 2008; accepted in revised form December 24, 2008. 


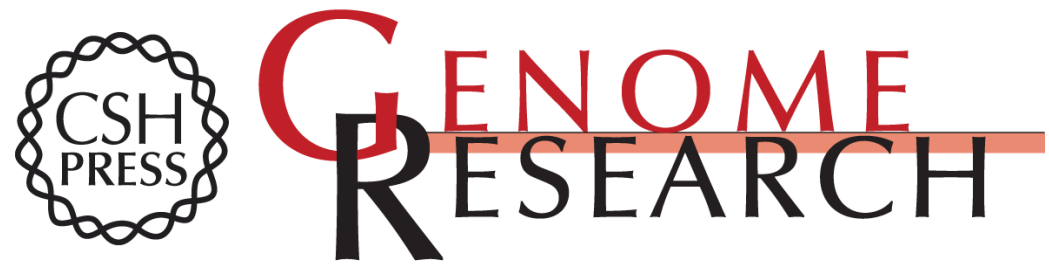

\section{The single mitochondrial chromosome typical of animals has evolved into 18 minichromosomes in the human body louse, Pediculus humanus}

Renfu Shao, Ewen F. Kirkness and Stephen C. Barker

Genome Res. 2009 19: 904-912 originally published online March 31, 2009

Access the most recent version at doi:10.1101/gr.083188.108

Related Content Why genomes in pieces? revisited: Sucking lice do their own thing in mtDNA circle game

David M. Rand

Genome Res. May , 2009 19: 700-702

References This article cites 35 articles, 6 of which can be accessed free at:

http://genome.cshlp.org/content/19/5/904.full.html\#ref-list-1

Articles cited in:

http://genome.cshlp.org/content/19/5/904.full.html\#related-urls

License

Email Alerting Receive free email alerts when new articles cite this article - sign up in the box at the Service top right corner of the article or click here.

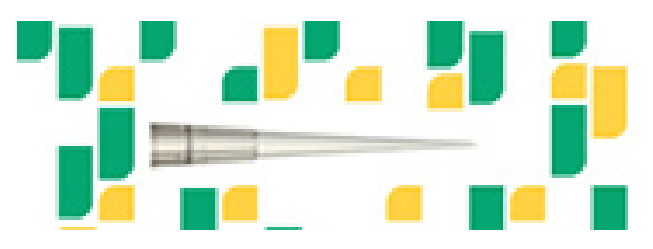

Focused on your science.

To subscribe to Genome Research go to:

https://genome.cshlp.org/subscriptions 